UDC 347.428

LBC 65.272.21

\title{
TERMINATION OF INDEPENDENT GUARANTEE: SOME PROBLEMS AND WAYS OF THEIR SOVLING
}

\author{
Mariya V. Khadeeva \\ Public joint-stock company “Rosgosstrakh Bank”, Kutafin Moscow State Law University, \\ Moscow, Russian Federation
}

\begin{abstract}
Introduction: the article is devoted to the problem of termination of obligations under independent guarantee for the reasons not directly provided by Art. 378 of the Civil Code of the Russian Federation.

For this purpose, the author examines a number of theoretical and practical problems the banks experience in connection with the imperfection of the legal regulation of the termination grounds for independent guarantee. By applying the scientific methods, primarily, the method of system analysis, the author identifies a number of issues related to the termination of independent guarantee due, in particular, to lack of judicial practice. Results: according to the author, the termination of bank guarantee, for the grounds not expressly provided for by clause 1 and clause 2 of Art. 378 of the Civil Code of the Russian Federation, is possible, but it is associated with some peculiarities. The termination of independent guarantee is possible for the general grounds for termination of obligations specified in Chapter 26 of the Civil Code of the Russian Federation. The inclusion in the bank guarantee the termination clause on the grounds other than those provided by Clause 1 and Clause 2 of Art. 378 of the Civil Code, is complicated by some circumstances, including the lack of a formed judicial practice on this issue. It seems that this is possible according to paragraph 4 of the Resolution of the Plenum of the Supreme Arbitration Court of the Russian Federation of March 14, 2014 No. 16 "On Freedom of Contract and Its Limits" and the content of Art. 378 of the Civil Code of the Russian Federation. The law does not prohibit the conclusion of the guarantor's agreement with the beneficiary before granting independent guarantee, which stipulates the specific circumstances upon which the independent guarantee may terminate and include in its text the grounds for termination stipulated in the relevant agreement, but not directly listed in Art. 378 of the Civil Code of the Russian Federation. Paragraph 4 of Art. 368 of the Civil Code also allows the term of reduction or increase in the amount of the guarantee when a certain period or a certain event occurs, which can be regarded as a cancelable condition (clause 2 of Art. 157 of the Civil Code of the Russian Federation). Thus, it can be assumed that in the event of the certain circumstances that entail a reduction of obligations under the guarantee to zero, the obligation under it can be terminated.
\end{abstract}

Conclusions: in connection with the lack of judicial and law enforcement practice and misunderstanding by the participants of the civil turnover of the freedom limits of determining the terms of transactions, the author offers the inclusion in the Civil Code of the provision similar to what is contained in the Uniform Rules for Guarantees on Demand (URGD No. 758): the effect of independent guarantee is terminated "if there is no amount left that may be paid according to the guarantee".

Key words: independent guarantee, bank guarantee, termination of obligation, beneficiary, freedom of determining the conditions.

УДК 347.428

ББК 65.272 .21

\section{ПРЕКРАЩЕНИЕ НЕЗАВИСИМОЙ ГАРАНТИИ: НЕКОТОРЫЕ ПРОБЛЕМЫ И ПУТИ ИХ РЕШЕНИЯ}

\author{
Мария Викторовна Хадеева \\ Публичное акционерное общество «Росгосстрах Банк», \\ Московский государственный юридический университет им. О.Е. Кутафина (МГЮА), \\ г. Москва, Российская Федерация
}


Введение: статья посвящена проблемам прекращения обязательств по независимой гарантии по основаниям, прямо не предусмотренным ст. 378 ГК РФ. С этой целью автор изучает ряд теоретических и практических проблем, возникающих у банков в связи с несовершенством правового регулирования оснований прекращения независимой гарантии. С помощью методов научного познания и, прежде всего, метода системного анализа выявлен ряд проблем, связанных с прекращением независимой гарантии, и обусловленных, в том числе, отсутствием сформированной судебной практики.

Результаты: автор указывает на то, что прекращение банковской гарантии по основаниям, прямо не предусмотренным п. 1 и п. 2 ст. 378 ГК РФ, в целом возможно, но сопряжено с некоторыми особенностями.

Так, прекратить независимую гарантию возможно по общим основаниям для прекращения обязательств, указанным в главе 26 ГК РФ.

Включение в банковскую гарантию условия о ее прекращении по основаниям, отличным от тех, что предусмотрены п. 1 и п. 2 ст. 378 ГК РФ, осложнено некоторыми обстоятельствами, в том числе отсутствием сформированной судебной практики по данному вопросу. Однако, как представляется, это возможно с учетом позиции, высказанной в п. 4 Постановления Пленума ВАС РФ от 14.03.2014 г. № 16 «О свободе договора и ее пределах», и содержания ст. 378 ГК РФ. Закон не запрещает гаранту с бенефициаром до предоставления независимой гарантии заключить соглашение, в котором предусмотрены конкретные обстоятельства, при наступлении которых независимая гарантия может прекратиться, и включить в ее текст основания для прекращения, предусмотренные соответствующим соглашением, но при этом напрямую не перечисленные в ст. 378 ГК РФ.

Пункт 4 ст. 368 ГК РФ также допускает наличие условия об уменьшении или увеличении суммы гарантии при наступлении определенного срока или определенного события, которое можно рассматривать как некое отменительное условие (п. 2 ст. 157 ГК РФ). Можно предположить, что при наступлении определенных обстоятельств (предусмотренных в тексте независимой гарантии), которые влекут снижение обязательств по гарантии до нулевого значения, обязательство по ней может быть прекращено.

Выводы: учитывая отсутствие сформированной судебной и правоприменительной практики, а также непонимание участниками гражданского оборота пределов ограничения свободы в определении условий сделок, представляется целесообразным включение в ГК РФ положения, аналогичного тому, что содержится в Унифицированных правилах для гарантий по требованию (URDG № 758): действие независимой гарантии прекращается, «если не осталось суммы, которая может быть по ней выплачена».

Ключевые слова: независимая гарантия, банковская гарантия, прекращение обязательств, бенефициap, свобода в определении условий.

На практике при работе с банковскими гарантиями кредитные организации сталкиваются с различными вопросами, связанными с прекращением обязательств по гарантии, в том числе, возможно ли прекратить обязательство по основаниям, отличным от тех, что прямо не предусмотрены в п. 1 и п. 2 ст. 378 Гражданского кодекса Российской Федерации (далее - ГК РФ).

Например, предположим, что банком была выдана гарантия, содержащая условие, что обязательства по гарантии уменьшаются в случае предоставления определенных документов. В итоге все вышеуказанные документы были предоставлены, что позволило уменьшить размер обязательств по гарантии до нуля. Соответственно возникает частный вопрос - является ли снижение обязательств по гарантии до нуля (без проведения выплат) основанием для ее прекращения? А далее напрашиваются общие:
- требуется ли в гарантии прямое указание на прекращение обязательств по ней при наступлении данного обстоятельства?

- правомерно ли предусматривать (любые) иные основания для прекращения, которые не указаны в ст. 378 ГК РФ?

- применяются ли общие основания для прекращения независимой гарантии, предусмотренные главой 26 ГК РФ?

Пожалуй, начнем с ответа на последний вопрос, так как он представляется нам наиболее простым. В доктрине давно сформировано мнение по вопросу применения общих оснований, предусмотренных ГК РФ для прекращения обязательств по независимой гарантии. Специальные правила о прекращении гарантии включают в себя некоторые общие основания прекращения гражданско-правового обязательства. Так, например, уплата гарантом бенефициару суммы, на которую выдана гарантия, означает надлежащее исполнение обя- 
зательства, что признается общим основанием прекращения всякого обязательства (п. 1 ст. 408 ГК РФ); отказ бенефициара от своих прав по гарантии путем письменного заявления об освобождении гаранта от его обязательства может быть приравнено к прощению долга (ст. 415 ГК РФ) [1; 6].

Что касается иных общих оснований прекращения гражданско-правового обязательства, то исходя из содержания норм, их устанавливающих, нет никаких препятствий для их применения и к обязательствам, вытекающим из независимой гарантии [2]. В качестве подтверждения указанной позиции можно привести любопытное решение, согласно которому обязательства по банковской гарантии прекращается по основаниям, предусмотренным ст. 416 ГК РФ в связи с отзывом у кредитной организации лицензии на осуществление банковских операций[3; 4]. Но к сожалению, как представляется, ни одно из перечисленных оснований, с которыми глава 26 ГК РФ связывает факт прекращения обязательств, не применимо к нашей конкретной ситуации.

Вернемся к остальным ранее поставленным вопросам: может ли гарант включать в текст независимой гарантии условия для ее прекращения, не предусмотренные п. 1 и п. 2 ст. 378 ГК РФ? Здесь необходимо отметить, что сформированная судебная практика по данному вопросу отсутствует, но имеется ряд судебных решений, которые далее будут нами проанализированы.

Так рассмотрим Постановление арбитражного суда Московского округа от 29.09.2016 г. по делу № А40-180944/15. Суд пришел к следующему выводу: «Возможность гаранта включать те или иные обстоятельства в качестве условий для прекращения банковской гарантии в действующем законодательстве предусмотрена в ч. 2 ст. 378 ГК РФ. Согласно данной норме независимой гарантией или соглашением гаранта с бенефициаром может быть предусмотрено, что для прекращения обязательства гаранта перед бенефициаром необходимо возвратить гаранту выданную им гарантию. Каких-либо иных прав гаранта по самостоятельному включению новых условий для прекращения обязательств по банковской гарантии действующее законодательство не содержит». Иными словами, суд подтвердил правомерность включения в гарантию условия, согласно которому для прекращения обязательства по независимой гарантии достаточно только возврата, однако указывает на то, что список оснований, содержащийся в ст. 378 ГК РФ (п. 1 и п. 2), по которым можно прекратить гарантию, является закрытым.

Но при оценке данной судейской позиции необходимо учитывать ряд обстоятельств. Во-первых, указанное условие было включено в банковскую гарантию, выданную в порядке, предусмотренном Федеральным законом от 05.04.2013 г. № 44-Ф3 «О контрактной системе в сфере закупок товаров, работ, услуг для обеспечения государственных и муниципальных нужд» (далее - Закон № 44-Ф3). Во-вторых, условие, которое было предметом негодования со стороны государственного заказчика, было сформулировано следующим образом: «...обязательства гаранта перед бенефициаром по настоящей банковской гарантии прекращаются в случае прекращения действия государственного контракта в силу его досрочного расторжения или иного прекращения обязательств сторон государственного контракта по иным обстоятельствам...». Учитывая, что требование по гарантии зачастую предъявляется после расторжения государственного контракта, когда подрядчик не возвращает неотработанный аванс, то включение данного условия очевидно нарушает публичные интересы. Поэтому полагаем, что само по себе решение суда в пользу государственного заказчика выглядит вполне закономерным (хотя можно не согласиться с приведенным обоснованием, изложенным в мотивировочной части). Вызывает удивление, как такая банковская гарантия была принята бенефициаром в связи с ее несоответствием Закону № 44-ФЗ. Учитывая изложенное, полагаем, что указанное решение суда не является показательным.

Рассмотрим еще одно судебное решение - Постановление Девятого арбитражного апелляционного суда от 20.03.2013 г. по делу № А40-135534/2012-133-1024, в котором содержалась следующая формулировка: «В соответствии с п. 9 Банковской гарантии перечисляются следующие условия ее прекращения: 
- с момента вступления в законную силу решения и/или постановления и/или определения арбитражного суда Смоленской области по делу № А62-4043/2011 об удовлетворении требований Принципала».

К сожалению, в данном случае суд не рассматривал вопрос о допустимости включения данной формулировки в текст банковской гарантии, а само судебное разбирательство было связано с прекращением банковской гарантии в связи с ее возвратом. Вышеприведенное решение лишь подтверждает, что на практике кредитные организации включают в гарантии «нетрадиционные» условия для их прекращения.

К сожалению, каких-либо других судебных решений, предметом которых был бы вопрос, связанный с включением в текст независимой гарантии условий о ее прекращении, отличных от перечисленных в ст. 378 ГК РФ, найти не удалось.

Так что же, неужели нельзя предусмотреть иные правила прекращения (не указанные в ст. 378 ГК РФ), неужели участники гражданского оборота настолько ограничены в определении условий сделки?

В целом допускается изменение условий, предусмотренных законом для односторонней сделки, которые прямо не указаны в качестве императивных или диспозитивных. Это подтверждается в п. 4 Постановления Пленума ВАС РФ от 14.03.2014 г. № 16 «О свободе договора и ее пределах», в котором указано, что нормы ст. 410 ГК РФ, устанавливающие предпосылки прекращения обязательства односторонним заявлением о зачете, не означают запрета соглашения договаривающихся сторон о прекращении неоднородных обязательств или обязательств с еще не наступившими сроками исполнения и т. п.

Следуя этой логике, гарант и бенефициар вправе договориться о прекращении обязательств по независимой гарантии по основаниям, прямо непрописанным в п. 1 ст. 378 ГК РФ. И этот тезис находит свое подтверждение в пп. 4 п. 1 ст. 378 ГК РФ, где прямо указано, что обязательство по независимой гарантии может прекращаться при наличии соответствующего соглашения гаранта с бенефициаром [3]. При этом закон не запрещает заключить такое соглашение до предоставления независимой гарантии и включить в ее текст основания для прекращения, предусмотренные соглашением между бенефициаром и гарантом, но при этом напрямую не перечисленные ст. 378 ГК РФ.

Но вернемся к нашему частному случаю. Что же делать, когда гарантия уже выдана и отсутствует возможность дополнительно урегулировать вопрос о ее прекращении (бенефициар не заинтересован ни в предоставлении отказа от прав, ни в заключении соглашения)?

Пункт 4 ст. 368 ГК РФ допускает наличие условия об уменьшении или увеличении суммы гарантии при наступлении определенного срока или определенного события, то есть закон прямо допускает включение в независимую гарантию отменительного условия (п. 2 ст. 157 ГК РФ). Таким образом, можно предположить, что при наступлении определенных обстоятельств (предусмотренных в тексте независимой гарантии), которые влекут снижения обязательств по гарантии до нулевого значения, обязательство по ней может быть прекращено. При этом, несмотря на очевидность такого вывода, в целях устранения каких-либо сомнений относительно судьбы выданной гарантии, рекомендуем включать в ее текст прямое указание на прекращение при снижении обязательств до нулевого значения.

\section{Выводы}

В заключении отметим, что выводы о допустимости применения тех или иных правовых конструкций, изложенные в настоящей статье, как уже было отмечено ранее, не подкреплены реальными примерами судебной практики. Учитывая, что толкование тех или иных норм права судом иногда вызывает удивление, а свобода в определении некоторых условий сделок неоправданно ограничивается судом, участники гражданского оборота будут с осторожностью смотреть на включение в независимую гарантию «нетрадиционных» условий для ее прекращения до тех пор, пока законодатель прямо не выскажется относительно них. При этом в Унифицированных правилах для гарантий по требованию (URDG № 758) предусмотрено, что действие независимой гарантии прекращается, «если не осталось суммы, которая может быть по ней выплачена». Представляется целесообразным включение аналогичного положения в ГК РФ. 


\section{СПИСОК ЛИТЕРАТУРЫ}

1. Брагинский, М. И. Договорное право. Общие положения (книга 1) / М. И. Брагинский, В. В. Витрянский. - Доступ из справ.-правовой системы «КонсультантПлюс».

2. Залог, банковская гарантия и другие способы обеспечения исполнения обязательств : Постатейный комментарий главы 23 Гражданского кодекса Российской Федерации / под ред. Б. М. Гонгало, П. В. Крашенинникова. - М. : Статут, 2010. - Доступ из справ.-правовой системы «КонсультантПлюс».

3. Замотаева, Т. Б. Проблемы правового регулирования независимой гарантии / Т. Б. Замотаева // Законы России: опыт, анализ, практика. -2016. № 1. - Доступ из справ.-правовой системы «КонсультантПлюс».

4. Определение Верховного суда РФ от 14.12.2016№ 305-ЭС16-16540 по делу № А40-161430/ 2015. - Доступ из справ.-правовой системы «Консультант Плюс».

5. Постановление Арбитражного суда Московского округа от 27.01.2017 № Ф05-20137/2016 по делу № A40-76451/2016. - Доступ из справ.-правовой системы «КонсультантПлюс».

6. Саркисян, А. В. Об отказе от права и его последствиях / А. В. Саркисян, Д. А. Новосельнов // Вестник экономического правосудия Российской Федерации. - 2017. - № 4. - Доступ из справ.-правовой системы «КонсультантПлюс».

7. Унифицированные правила для гарантий по требованию, включая типовые формы (URDG 758). Редакция 2010 г. (Публикация Международной торговой палаты № 758). - Доступ из справ.-правовой системы «КонсультантПлюс».

\section{REFERENCES}

1. Braginskiy M.I., Vitryanskiy V.V. Dogovornoe pravo. Obshchie polozheniya (kniga 1) [Contract Law.
General Provisions (Book 1)]. Access from Reference Legal System "KonsultantPlyus".

2. Gongalo B.M., Krasheninnikov P.V., eds. Zalog, bankovskaya garantiya i drugie sposoby obespecheniya ispolneniya obyazatelstv: Postateynyy kommentariy glavy 23 Grazhdanskogo kodeksa Rossiyskoy Federatsii [Pledge, Bank Guarantee and Other Ways of Securing the Fulfillment of Obligations: An Itemized Commentary to Chapter 23 of the Civil Code of the Russian Federation]. Moscow, Statut Publ., 2010. Access from Reference Legal System "KonsultantPlyus".

3. Zamotaeva T.B. Problemy pravovogo regulirovaniya nezavisimoy garantii [Problems of Legal Regulation of Independent Guarantee]. Zakony Rossii: opyt, analiz, praktika, 2016, no. 1. Access from Reference Legal System "KonsultantPlyus".

4. Opredelenie Verkhovnogo suda RF ot 14.12.2016 № 305-ES16-16540 po delu № A40161430/2015 [The Definition of the Supreme Court of the Russian Federation of December 14, 2016 no. 305-ES16-16540 on Case no. A40-161430/2015]. Access from Reference Legal System "KonsultantPlyus".

5. Postanovlenie Arbitrazhnogo suda Moskovskogo okruga ot 27.01.2017 № F05-20137/ 2016 po delu № A40-76451/2016 [Resolution of the Arbitration Court of the Moscow District of January 27, 2017 no. F05-20137/2016 on Case no. A40-76451/2016]. Access from Reference Legal System "KonsultantPlyus”.

6. Sarkisyan A.V., Novoselnov D.A. Ob otkaze ot prava i ego posledstviyakh [On Rejection of the Law and Its Consequences]. Vestnik ekonomicheskogo pravosudiya Rossiyskoy Federatsii, 2017, no. 4. Access from Reference Legal System "KonsultantPlyus".

7. Unifitsirovannye pravila dlya garantiy po trebovaniyu, vklyuchaya tipovye formy (URDG 758). Redaktsiya 2010 g. (Publikatsiya Mezhdunarodnoy torgovoy palaty № 758) [Uniform Rules for OnDemand Warranties, Including Standard Forms (URDG 758). Edition of 2010 (Publication of the International Chamber of Commerceno. 758)]. Access from Reference Legal System "KonsultantPlyus". 


\section{ВОПРОСЫ ЧАСТНОПРАВОВОГО РЕГУЛИРОВАНИЯ}

\section{Information about the Author}

Mariya V. Khadeeva, Head of the Division of Legal Support of Methodology of Credit and Trade Financing of Legal Management, Public joint-stock company "Rosgosstrakh Bank", Postgraduate Student of the Department of Banking Law, Kutafin Moscow State Law University, Sadovaya-Kudrinskaya St., 9, 123286 Moscow, Russian Federation, hadeeva_mariya@mail.ru.

\section{Информация об авторе}

Мария Викторовна Хадеева, руководитель направления правового сопровождения методологии кредитования и торгового финансирования Правовой дирекции Публичного акционерного общества «Росгосстрах Банк», аспирантка кафедры банковского права, Московский государственный юридический университет им. О.Е. Кутафина (МГЮА), ул. Садовая-Кудринская, 9, 123286 г. Москва, Российская Федерация, hadeeva_mariya@mail.ru. 